\title{
The Application of Energy-saving and Environmental-protection Materials in Landscape Design
}

\author{
Zhuoyu Zhang \\ Graduate Department \\ Tianjin Polytechnic University \\ Tianjin 300160, China \\ E-mail:zhangzhuoyu198363@163.com
}

\begin{abstract}
The development of the society has continually enhanced human material living quality, at the same time, human environmental-protection consciousness has been continually enhanced, and the opinion of energy saving and environment protection has gone into many aspects of human living. People have begun to know that natural resource is limited, and the human can not take from the nature unendingly. Everyone should make great efforts to make the harmony between human and nature. And the landscape design is the ligament between them without fail, and it is the industry with flourish life in recent years in China. It includes the urban square design with hundreds of thousand square meters and the courtyard design with a few square meters, and if the energy problem of landscape design can not be solved better, it will induce large of energy wastes. The problem how to work out real green landscape has been the problem that people more and more noticed. The selection of materials in the construction process of landscape design has become into the very important aspect to make green landscape undoubtedly.
\end{abstract}

Keywords: Harmony, Environmental protection, Energy saving

The technical advancement of modern science and the rapid development of social productivity have quickened up the course of human civilization. At the same time, the human society is facing a series of serious challenges of important environmental and developmental problems. The leap of population, the excess consumption of energy, the variance of climate, the environmental pollution, the destroyed zoology and other problems have threatened human existence and development. Before serious reality, people have to rescan and rejudge the present urban development view and value system that we trust. Many insight men have gradually cognized that the human is one part of the natural system and is closely linked with the environment supported by the natural system. In the process of the urban development and the construction, we must first consider the problem of ecological environment, and put it on the same important status with economy and society, at the same time, we must further survey the reasonable utilization problem of limited resource, respect the natural rule, follow the nature, realize the existence philosophy of harmony and intergrowth and the human value view.

In recent 20 years, the course of urban construction and urbanization are in the ascendant in China, and with the development of urbanization, the construction of urban park is unparalleled whether on speed or on amount. The landscape design of park which had not been noticed at past has been emphasized now. From traditional park to urban virescence and to the landscape of urban and village integration, the park layout design concept is being gradually deepened and perfected, and the domain is developing, and more and more products occur. The landscape design of China has gradually formed its own system in the continual development process. There are bad aspects and good aspects in the whole system. Therefore, we should develop excellences, avoid and correct wrong opinions in the landscape design. The green environment-protective landscape should be established and really serve for people.

\section{Main problems existing in the landscape design at present}

\subsection{The extravagance of design standard works unnecessary wastes}

The essential of the landscape on the natural meaning is the base of human existence, but not only the beautiful landscape, and it is human living area, so it must accord with the basic demand and certain cultural demand of public leisure, and its chance is mainly to create public opening space for the leisure activities, not the environmental beatification concept. The modern landscape design is not absorbed in creating concrete things or building certain picture any more, and it must create the new relationship between human and whole environment, and cause the occurrences of public space and communication space. Therefore, in the process of landscape design, more 
practicability must be considered, and a great deal of granites, marbles, stainless steels, glass curtains, super lamps and lanterns, import conduits and other expensive landscape materials are not used in the landscape design to make up so-called urban bright points, because it not only loses the natural beauty and harmonious beauty contained in China classical park, but also induces a sort of situation imitating each other and mingling with culture. And it not only wastes limited natural resources, but doesn't achieve anticipated effects for the design. The park landscape is a synthesis with multiple functions of society, nature and arts, which should not fulfill the social functions of ecology, environmental-protection, leisure and urban beautification, but also accord with the natural rule of botany, and embody the philosophy and individual style on the arts at the same time. So we should not emphasize the materials such as luxury and exquisite materials, but consider the cost and practicability of the landscape and its influence to the environment, and decrease meaningless burdens to the natural resource.

\subsection{The complication of simple design}

The complication of simple design is the usual problem occurring in modern landscape design. In the process of landscape design, though few resources can obtain effects, but complex representation is often used to induce wastes with different forms. For example, the road virescence in some house areas can adopt simple design method such as planting footway trees to achieve good effects. But in many luxury house areas, many unnecessary decorations are added to induce wastes of resources. The peripheral Chinese pines around the Monument to the People's Heroes in 1950s in Beijing and the poplar tree street on the Beijing airdrome in 1980s are good examples of simple design. The simplicity can sometimes embody status and the austerity is the concept. So there is not necessary to pursue so-called "bright point", and more exterior ornament looks unstable. Large of ground lays occupy the proportion of greenbelt, which destroys the whole harmony of the landscape and induce necessary wastes of natural resource.

\subsection{The rockiness of deficient green shadow}

The deficient green shade and excessive square lays are other problems in the design of present landscape. The trees planted newly can not form green shade, and many greenbelts are occupied by various lays, which make the area of greenbelts more reduced. Many waterscapes use concretes to make pool bottom and shores, which obstructs the land atmosphere and can not circulate the ecological system favorably.

Facing these problems existing in the landscape design, designers strive to look for methods to solve these problems. In the exploring process, the design path and design concept are gradually formed to fit Chinese situation.

\section{The basic concepts to solve the problems in the process of discussion}

\subsection{The application of the sustainable development design view in the landscape design}

The environment and energy crisis is more serious to China which is in the course of industrialization than the Europe and American countries in after-industrial times, and this situation is pricking up in the super-urbanization course. The environment and the energy are a pair of contradictions that can not be obtained together for the developing countries, because the development must consume large of energies and destroy environment, so we can not follow the same old disastrous road in the process of the development, and we should summarize gain and loss and find out our own development mode from developed countries.

This sort of new development tendency must induce a sort of new design concept, i.e. the design concept of sustainable development. The design view of sustainable development is to protect ecology and create human existence environment of sustainable development, which can not fulfill the human demands to the environment, but also can not take the destroyed environment as the cost and consider the benefits of offspring, and it is the basic task of 21st century environmental landscape design. The concept of sustainable development puts forward the ethic obligation and social responsibilities assumed by the landscape designers. The landscape designer's obligation is to put the landscape, construction and basic establishment into the continually development and great system composed by all artificial things and natural things to consider problems, which can effectively supervise large of wastes and unequal occupation induced by this sort of behavior. The effective utilization and economy to the resources are modern landscape designer's responsibility, and we should understand this mission.

With the further deterioration of environment and energy crisis, the concept of sustainable development has been a sort of application method to deal with the triangle among environment, healthy and development, and been the center of gravity of modern landscape and architecture research. The concept of sustainable development makes designer and owner reconsider the rationality of the design from the view of ethic and landscape consumption, which changes the organization method in the traditional design and advocates the design of subtraction in the design process, even only leaves the core content of ethic relation between human and subjective world. The utilizations of regeneration materials and the extension of lifecycle of materials through protection can reduce the amount of demands of materials. The materials which lose efficacies can be simply separated and dismantled, which can not influence the continual use of the materials that can exert efficacies. 


\subsection{The application of ecology and ecological design in the landscape design}

The ecology is a sort of science about the relation between human and nature. The western environment and energy crisis pushed the modern ecology to the historical stage, but the ecology concept of China has not gone into public view, and the ecology is equaled with green, even it had been a camouflage of the tree replantation which seriously destroys the ecology for a time. The ecology is the basic subject of the landscape ecological layout, and the design of landscape locale should follow the ecological principle. The modern landscape design understands the landscape locale as a part of natural ecological system, seriously and reasonably uses natural resource, reduces the destruction to the ecosystem to protect natural resource, and reduces the invasion of landscape local to the nature to the least level and accordingly sustain the integrity of natural system, and establishes regional ecological space based on the principle of ecology. The measure of ecological design is used to pursue natural atmosphere and obey natural living environment. The sustainable development of the landscape is the final objective of ecological layout. In the design of community environment, the ecological design is embodied in displaying nature, weakening building, advocating the harmonious status between human and propagation. Therefore, when we implement concrete environment design, we should advocate creating natural environment and making biology more diversifiable.

\section{The application of environmental-protection and energy-saving materials in future landscape design}

\subsection{The introduction of environmental-protection and energy-saving materials}

Facing so many problems, the landscape designers are exploring their own development roads in continual practices and looking for the methods to solve problems. From courtyard design to square design, from greenbelt plan to urban layout, the environment-protective and energy-saving materials have gone into every part of landscape design and been exerting important functions, and the materials have become into the important correction and selection to face the challenge of ecological environment crisis and meditate human behaviors for modern human society, that is to say, we should change the predatory even devastating development mode that takes environment scarification as cost, make economy and society and environment develop harmoniously, and make landscape design walk up the road of good circulation. We should not only protect circumjacent ecological environment, but also reuse energies and reduce the irreproducible solid castoff which seriously harms environment. We should continually recognize that the environment protection is the premise and base of social development, and we should use environment-protective and energy-saving materials in landscape design, change old view of energy, which can not only save limited natural resources and benefit offspring, but protect environment and create good environment for our existence.

In the day that the scientific technology changes quickly, many scientific research results about materials of landscape have been applied in landscape design, which has brought concrete advantages for us. Some human imaginations in former days has become into realism and been exerting irreplaceable functions in actual living.

\subsection{The applications of three sorts of environmental-protection and energy-saving materials in the landscape design}

\subsubsection{SF synthetic material}

The SF synthetic material is a sort of new high strength synthetic material which takes old plastic and useless coal powder as main raw materials to be processed through scientific machining craftwork and activator. The character of SF synthetic material is the nonuse of wood, which can protect environment and solve the problem of deficient wood when the natural forest is protected. In many examples of landscape design, we can see that large numbers of woods are used to make park chair, flower frame, tree pool and other basic establishments in the earth project, which can induces not only meaningless wastes of forest resource, but also some unavoidable deficiencies such as easy cauterization, short use life and continual replacing. Therefore, the wood resource will be consumed endlessly, but SF synthetic material will successfully solve this problem, and it is synthesized by castoff through harmless disposal, and it can not only reduce the harm of castoff to the environment, but also replace woods to be the important materials in landscape design. Its anticorrosive and anti-insect abilities can make it not only possesses the advantage that woods don't have, but also ensures that its using year is longer than woods and its repairing charge is fewer than woodwork. With the birth of green energy-saving and environment-protective material, SF synthetic material, it will be extensively adopted in many projects such as architecture, square, road and urban construction, and it will add a beautiful landscape line for our life and bring healthy and harmless environment to us.

\subsubsection{New pigment disposal technology: envelope titanium white}

Large numbers of color brick will be used to lay earth or build flower pool in landscape design, and many production flows of pigment will produce much pollution and depredate the environment. Therefore, it is the key problem to eliminate the pollution of pigment in the production process for building environment-protective landscape.

The titanium oxide is a sort of optimal white pigment, and because of its highly chemical stability and excellent pigment performance, it is extensively applied in various domains of national economy such as porcelain, plastic, medication, cosmetic, dope and latex. It offers based for good landscape design and adds beautiful trait for the urban 
landscape.

\subsubsection{Lava}

Except for general characteristics of common stone materials, the lava possesses its own special style and unusual function. Comparing with granite, the low radioactivity of basalt can make it safely used in human living locales. The lava can resist efflorescence and climate, wear well, absorb sound and reduce noise to improve hearing environment. It is simple and unsophisticated and avoids dizzy to improve the vision environment. It can absorb water, resist slide and obstruct heat to improve the feeling environment. Its special "breath" function can condition the air humidity to improve the environment. Its various special advantages can fulfill the new style that modern human pursues primitive simplicity and nature and advocates green environment-protection. Because of its firm stone nature, the lava can produce super thin flagstone material which blare degree can achieve above 85 through extractive grinding. Its color and luster is bright and pure, and its appearance is elegance and sobriety, so it is extensively used in various exterior wall decorations, urban road square and earth laying in house area and it can offer basic materials for environment-protective landscape.

\section{Conclusions}

At present, the quick urbanization course in China has made the urban environment construction face austere challenge. The landscape is the important part of the urban ecosystem, and it has important function to enhance the function and healthy development of the urban ecosystem. The occurrence of new term always indicates the occurrences of new problem, new concept, new consultation and disputation, and the landscape design is presenting this character since it went into China for almost ten years. It makes traditional theory which takes the taste as the base give place to the pragmatic ecological design which combines professional knowledge and social demands with natural system. The ecological design is one very important aspect to decide whether the landscape design and environment quality are successful, and the effective path to create the landscape with better environment, quality and safety. And the energy-saving and environmental materials can exert important functions in the development. The use functions of energy-saving and environmental materials will be continually perfected in future development process and serve for real green environment-protective landscape. We can forecast that the energy-saving and environmental materials must replace existing materials and exert irreplaceable function in the landscape design.

\section{References}

An, Huaiqi. (2006). Chinese Landscape Architecture. Shanghai: Tongji University Press.

An, Huaiqi. (2006). New Landscape Design. Shanghai: Tongji University Press.

Miguel Ruano. (2007). Eco-urbanism Sustainable Human Settlements: 60 Case Studies. Beijing: China Electric Power Press.

Miguel Ruano. (2007). The Theory and Measurement Methods for The Sustainable Development. Beijing: China Architecture \& Building Press.

The 2nd International Conference on Intelligent Green and Energy Efficient Building. (2006). Memories on Intelligent Building and Green Building 2. Beijing: China Architecture \& Building Press.

Zhang, Yuxiang. (2002). Manual of Green Building Construction Materials. Beijing: Chemical Industry Press. 